\title{
A LEITURA LITERÁRIA É UM CONCEITO DIDÁTICO? ${ }^{1}$
}

\section{LA LECTURE LITTERAIRE EST-ELLE UN CONCEPT DIDACTIQUE?}

\author{
https://doi.org/10.20873/uft2179-3948.2020v11n3p20-38
}

\author{
Brigitte Louichon ${ }^{2}$ \\ Tradução de \\ Dayb M. Oliveira dos Santos e Neide Rezende ${ }^{3}$
}

\begin{abstract}
Resumo: A leitura literária é uma noção bastante presente em didática da literatura. Em consequência, as acepções são muito diversas. A partir de um corpus de artigos ou de obras bem conhecidas, claramente centradas na leitura literária, faz-se a comparação de definições dadas da leitura literária e de discursos a respeito. Num segundo momento, e a partir de um segundo corpus de contribuições, serão apresentados os usos do sintagma leitura literária para tentar cercar as acepções em discurso.
\end{abstract}

Palavras-chave: leitura literária; didática da literatura

Résumé : La lecture littéraire est une notion très présente en didactique de la littérature. Pour autant les acceptions sont assez diverses. A partir d'un corpus d'articles ou d'ouvrages bien connus, clairement centrés sur la lecture littéraire, sont comparées les définitions données de la lecture littéraire et les discours tenus à propos de celle-ci. Dans un deuxième temps, et à partir d'un deuxième corpus de contributions, seront mis au jour les usages du syntagme lecture littéraire pour tenter d'en cerner les acceptions en discours".

Mots-clés: lecture littéraire; didactique de la littérature

Em 1995, durante o Colóquio de Louvain La Lecture Littéraire en Classe de Français[A Leitura Literária na Aula de Francês], Yves Reuter abriu seu discurso nos seguintes termos:

Apesar de uma infinidade de livros mais ou menos focados nesse assunto, [...] a leitura literária tem sido não somente pouco estudada em seu real funcionamento, mas

\footnotetext{
${ }^{1}$ Texto originalmente publicado em: LOUICHON, Brigitte. La lecture littéraire est-elle un concept didactique? In Daunay,B.,Reuter, Y.\& Schneuwly, B.(dir.). Les concepts et les méthodes en didactique du français. Namur:AIRDF-PUN, 2011. p.195-216.

${ }^{2}$ Brigitte Louichon é professora da Faculdade de Educação da Universidade de Montpellier e membro do LIRDEF (Laboratoire Interdisciplinaire de Recherche en Didactique, Éducation et Formation), da mesma universidade. Em parceria com Annie Rouxel, organizou os livros Du corpus scolaire à la bibliothèque intérieure (Presses Universitaires de Rennes -PUR, 2010) e La littérature en corpus - Corpus implicites, explicites, virtuels (Canopé - CRDP de Dijon, 2009).

${ }^{3}$ Dayb M. Oliveira dos Santos é Doutoranda em Ciências da Educação na Universidade de Montpellier, sob a orientação de Brigitte Louichon e co-orientação de Neide Luzia de Rezende, professora da Faculdade de Educação da Universidade de São Paulo - daybmanuela@yahoo.com.br; neirez@usp.br.
} 
também pouco definida. [...] A “leitura literária” é uma abstração, um pré-conceito. (REUTER, 1996, p. 33-34).

Em 2002, Jean-Maurice Rosier se refere à expressão como protonoção (ROSIER, 2002). No mesmo ano, Jean-Louis Dufays fala em conceito (DUFAYS, 2002), mas em 2005, ele preferirá noção (DUFAYS et al., 2005). Em 2007, Bertrand Daunay transformou-o em um paradigma (DAUNAY, 2007), e posteriormente, junto com Jean-Louis Dufays, falando de leitura e literatura, ele usa o termo "conceito" (DAUNAY; DUFAYS, 2007).

Parece que em poucos anos passamos do pré-conceito ao conceito. Isso supõe minimamente que essa noção pode ser definida e que essa definição seja aceita pelo conjunto da comunidade científica. Por conseguinte, ela deve ser reproduzida em termos semelhantes por essa comunidade.

Gostaria, então, de retomar esta questão em uma dupla perspectiva. A partir de um corpus de artigos ou livros já bastante conhecidos, claramente centrados na leitura literária, compararei as definições da leitura literária e os discursos produzidos a seu respeito. Posteriormente, a partir de um segundo corpus de contribuições, procurarei identificar os usos do sintagma "leitura literária" para tentar delimitar as acepções.

\section{Definições}

Vou me ater, aqui, exclusivamente à leitura literária enquanto objeto que remete ao campo ou ao discurso didático 4 .

A origem do uso didático da noção de leitura literária pode ser datada dos anos 1990. O Colóquio de Louvain em 1995, organizado por Jean-Louis Dufays, Louis Gemenne e Dominique Ledur e intitulado La lecture littéraire en classe de français: quelle didactique pour quels apprentissages? [Leitura literária na aula de francês: qual didática, para quais aprendizagens?], constitui a primeira problematização da noção no campo do ensino ${ }^{5}$. Ao mesmo tempo, Annie Rouxel publicava Enseigner la lecture littéraire [Ensinar a leitura literária], embora seja importante destacar que ela não participou do colóquio de Louvain ${ }^{6}$. Em seu livro, a noção de leitura literária parece (retrospectivamente) estar em processo de

\footnotetext{
${ }^{4}$ No que diz respeito à noção no campo da teoria literária, pode-se consultar Théories et pratiques de la lecture littéraire (GERVAIS e BOUVET, 2007).

${ }^{5} \mathrm{O}$ projeto de pesquisa "Leitura literária" dirigido por Jean-Louis Dufays e subsidiado pela CFB (Communauté française de Belgique) foi realizado entre 1992 e 1996.

${ }^{6}$ Seu nome não aparece no sumário do evento e em seu livro, Annie Rouxel apenas menciona o Colóquio de Louvain na introdução, como um acréscimo de última hora.
} 
elaboração. Prova disto é que o sumário não inclui em momento algum a expressão leitura literária. Por outro lado, nele encontramos um ponto epistemológico sobre a leitura, que lista e coloca em perspectiva os trabalhos de Jauss, Picard, Eco, Iser e Bakhtin. No restante do livro, as noções de erro de leitura, de distância, de ilusão referencial, de sentido lacunar etc. são utilizadas de modo a propor uma leitura literária escolar, em que o livro se detém.

Podemos, portanto, datar com bastante precisão o momento em que a expressão leitura literária se instala no campo didático. Mas podemos considerar que, a partir da edição de Pratiques $^{7}$, L'interpretation des texte [A interpretação dos textos] em 1992, a ideia já estava no ar. $\mathrm{O}$ artigo fundador de Martine Burgos Lecteurs experts, lecteurs convers, de quelques lecteurs en lycée professionnel et ailleurs [Leitores especialistas, leitores leigos, alguns leitores no Ensino Médio profissional e em outros lugares] não contém a expressão, mas a noção já está presente $^{8}$ :

[...] um texto literário vai antes ao encontro da emoção, da identificação com que nos entregamos a um universo ficcional antes de ser apropriado pela reflexão, pela análise e pelo meta-discurso (BURGOS, 1992, p. 73).

Nos anos seguintes, a expressão é retomada e a noção é elaborada e conceitualizada. Em 2002, surgiram os programas curriculares das escolas primárias nos quais a expressão leitura literária fez sua entrada institucional (MEN, 2002a, p. 187). Ela pode ser encontrada em Documentos de Acompanhamento 9 (MEN, 2002b e MEN, 2003). A significação da expressão é muito ambígua nesses textos. Por vezes, pode parecer referir-se a uma leitura distanciada, em outras, à leitura de textos que remetem ao literário; mas também, a uma forma de leitura a ser privilegiada e, em outros momentos, a ser evitada (LOUICHON, 2007). Esse uso ambíguo manifesta a relativa instabilidade da noção. Ao mesmo tempo, sua inscrição no campo institucional confere a expressão uma existência didática definitiva. A partir disto, um certo número de artigos ou livros tentarão elucidar a noção. Eu escolhi dentre esses textos quatro que mostram esse desejo de elucidação.

\footnotetext{
${ }^{7}$ Nota de tradução: Revista francesa criada em 1974, com a perspectiva de renovação teórica dos conteúdos de ensino e de inovação pedagógica concernente à didática do francês, à linguística e à literatura.

${ }^{8}$ Gérard Langlade também inclui esse texto em seu corpo de artigos didáticos que destacam várias concepções de leitura literária (LANGLADE, 2009).

${ }^{9}$ Nota de tradução: Os documentos de acompanhamento constituem publicações oficiais temáticas ou focadas em uma área da educação francesa com o objetivo de apresentar textos e recursos para apoiar os professores em sua implementação (https://eduscol.education.fr/pid34302/les-sites-thematiques-eduscol.html).
} 


\subsection{Corpus}

- Em 2002, um curso de outono foi dedicado à "leitura e cultura literárias no ciclo de aprofundamento" por iniciativa da $\mathrm{DESCO}^{10}$. Momento no qual Annie Rouxel realiza uma intervenção numa perspectiva de vulgarização científica com objetivos praxeológicos. Sua contribuição é intitulada “Qu'entend-on par lecture littéraire?” [O que se entende por leitura literária?].

- Ainda em 2002, Catherine Tauveron publicou Lire la littérature à l'école [Ler a literatura na escola]. Esta obra de vulgarização para professores resulta dos trabalhos que a autora realizou no INRP (Institut National de la Recherche Pédagogique) por vários anos e nos quais se inspiram, pelo menos em parte, os programas curriculares de 2002. Começa com um capítulo intitulado "Spécificités et enjeux de la lecture littéraire" [Especificidades e desafios da leitura literária].

- Também em 2002, em Grenoble, durante o Troisièmes Rencontres des Chercheurs en didactique de la littérature ${ }^{11}$ [Terceiro Encontro de pesquisadores em didática da literatura], Jean-Louis Dufays apresenta uma comunicação sobre leitura literária como noção plural. O texto é reproduzido na segunda edição de Pour une lecture littéraire [Por uma leitura literária] (2005), sob o título La lecture littéraire: une notion plurielle ${ }^{12}$ [A leitura literária: uma noção plural].

- Em 2007, Bertrand Daunay publicou um resumo bastante notável État des recherches en didactique de la littérature [Estado da arte em didática da literatura]. Algumas páginas são dedicadas à La lecture littéraire: l'invention d'un nouveau paradigme didactique [Leitura literária: a invenção de um novo paradigma didático].

Esses quatro textos não têm o mesmo estatuto e uma leitura rápida é suficiente para ver as diferenças que existem entre a nota retrospectiva de Bertrand Daunay e a introdução de Lire la littérature [Ler a literatura]. Nem o público nem as questões são idênticas. No entanto, esses quatro textos têm em comum ter sido escritos por atores importantes no campo científico e

\footnotetext{
${ }^{10}$ Nota de tradução: DESCO: Direction de l'enseignement scolaire [Secretaria do ensino escolar]. Trata-se de uma secretaria ligada ao Ministério da Educação Nacional francês.

${ }^{11}$ Nota de tradução: Encontro anual dos pesquisadores em didática da literatura realizado desde os anos 2000 no contexto francófono, cuja existência e atuação foi de fundamental importância para o estabelecimento da didática da literatura como um campo de pesquisa específico, atualmente intitulado Rencontres des chercheur.e.s en didactique des littératures.

${ }^{12}$ Cuja primeira versão foi publicada na revista Tréma $\mathrm{n}^{\circ} 19$ (2002).
} 
didático, com distanciamento histórico suficiente para aceitar pensar sobre o próprio objeto. As grandes diferenças do ponto de vista do contexto enunciativo no qual se situam permitem perceber melhor os aspectos comuns.

\section{Um objeto problemático}

A leitura literária é uma "noção cujo caráter plural e problemático" requer "esclarecimento e explicitação" (Dufays ${ }^{13}$ ). É um "termo problemático" cuja "existência terminológica" é "frágil” e para o qual uma "definição consensual” não é fácil. Ninguém saberia definir o que é uma leitura literária sem fazer oposição a uma outra definição, afirma Bertrand Daunay. Catherine Tauveron, cujo propósito inscreve-se em um outro contexto enunciativo e que parece apoiar-se em uma definição unívoca da leitura literária, deixa perceber a existência de outras discussões possíveis. Nesse sentido, ela evoca a leitura literária "que pode assumir várias formas" e se fundamenta na "leitura literária, assim compreendida", expressões estas que permitem supor a possibilidade de compreendê-la de outra maneira (TAUVERON, 2002, p. 1819).

\subsection{Uma virada epistemológica}

A elucidação necessária é então baseada em uma virada epistemológica, cujos contornos são bastante variados. Os trabalhos mais sistematicamente citados como constituintes da noção são aqueles de semiótica (particularmente os de Umberto Eco), de poética (Michel Charles) e os da escola de Constance (Iser e Jauss). Em seguida, vêm os teóricos da leitura literária (Michel Picard, Vincent Jouve, Bertrand Gervais). Essas referências constituem uma base comum, cujos perímetro e uso diferem. Com o intuito de adotar uma perspectiva suficientemente ampla, Bertrand Daunay acrescenta a essas referências os trabalhos americanos da corrente crítica reader's response. Significativamente, porém, Daunay não cita nenhum autor ou texto específico $^{14}$. Inversamente, Catherine Tauveron privilegia as proposições de Bertrand Gervais e de Michel Picard, ou seja, os autores que já haviam elaborado um conceito de leitura literária e que constituem o que poderíamos chamar de nível superior do substrato epistemológico. Annie Rouxel simplifica a proposição ao identificar quatro autores (Jauss, Iser, Eco e Picard), cujos "trabalhos estão na origem da leitura literária". Este relato das origens parece representar

\footnotetext{
${ }^{13} \mathrm{Na}$ continuidade da discussão, as indicações entre parênteses se referem ao corpus 1.

${ }^{14}$ Os textos de Louise Rosenblatt são os mais conhecidos.
} 
um tipo de base a partir da qual são fundadas as opções mais ou menos divergentes dos especialistas em didática. Jean-Louis Dufays, ao contrário, apresenta concepções diferentes da noção de leitura literária presentes no campo da didática do francês e da didática da literatura como o produto de trabalhos teóricos diferentes. Por exemplo, as concepções de Annie Rouxel ou de Catherine Tauveron remeteriam aos trabalhos de Stierle, de Marghescou, de Eco, formalizados por Gervais, enquanto aquela que Dufays preconiza, "o vaivém dialético entre distanciação e participação", seria devida a Michel Picard.

\subsection{A questão sociológica}

Essas referências teóricas remetem majoritariamente ao campo dos estudos literários. Ao mesmo tempo, elas devem ser relacionadas com um outro quadro, mais sociológico. Daunay (2007, p. 167) evoca "algumas abordagens sociológicas ou históricas das práticas culturais [que constituíram] um pano de fundo teórico dando elementos à justificativa da leitura literária”. Mais amplamente, a questão do estatuto da literatura na sociedade e do estatuto dos estudos literários nos currículos escolares, é determinante. Assim declara Catherine Tauveron: "a leitura literária é hoje uma das possíveis vias escolares para reconciliar as crianças com a leitura”. Baseada nos trabalhos de Roland Goigoux e Gérard Chauveau, ela fundamenta sua proposta em análises do fracasso escolar. Mesmo Annie Rouxel (2002, p. 30), cujo propósito parece escapar a esse questionamento sociológico, conclui afirmando que a leitura literária "é um meio prodigioso de estimular a criatividade dos alunos, de impulsionar processos interpretativos e, finalmente, de lutar contra o fracasso escolar e o iletrismo".

$\mathrm{O}$ artigo de Jean-Louis Dufays explicita as tensões presentes no campo da didática em relação à questão da leitura literária. À leitura literária é frequentemente levantada a objeção sobre a sua constituição como uma prática erudita, estetizante, centrada na subjetividade e cuja dimensão sociocultural construída parece ignorada.

Jean-Louis Dufays, assim como Bertrand Daunays, mostram que o que está especialmente em debate é a maneira pela qual os teóricos ou os especialistas em didática concebem a leitura literária. Quando a leitura literária é interrogada enquanto prática social ou escolar socialmente situada, é sobre a questão do distanciamento que os debates se detêm. 


\subsection{Uma definição pessoal}

É assim que cada uma das contribuições, propondo-se mais ou menos explicitamente elucidar o debate, na realidade resulta na proposição de uma definição pessoal da leitura literária. É isso o que mostra Annie Rouxel ao passar do título O que se entende por leitura literária? para "de minha parte, eu designo como leitura literária...".

Lembremos de memória estas definições.

Jean-Louis Dufays opõe uma concepção da leitura literária como arte do distanciamento a uma outra como participação. Ao final desse confronto, ele enuncia sua proposição de uma leitura literária concebida como um vaivém dialético entre esses dois polos, inspirando-se livremente no modelo de Picard.

Catherine Tauveron (2002, p. 20-21) oferece um patchwork de citações de Bertrand Gervais para ao final definir a leitura literária como leitura distanciada, o prazer da leitura literária é "um prazer gourmet" e "um ato singular de apropriação de um texto". Ela insiste ainda no fato de que "a leitura literária demanda naturalmente a troca".

Annie Rouxel postula que a leitura literária é o fato de "ler literariamente um texto literário", que é, portanto, uma questão de textos e de postura. O texto literário é um texto fundamentalmente polissêmico e a relação com este texto é feita de distância, de sensibilidade à forma, de lentidão e de prazer estético.

Bertrand Daunay com sua nota de síntese inscreve-se em uma perspectiva a priori diferente. Ele propõe uma visão panorâmica das coisas, o que deve excluir toda tomada de posição pessoal. Isto posto, o autor encerra sua exposição sobre as críticas que podem ser feitas a este novo paradigma, cuja utilidade e pertinência no campo da didática ele acaba por questionar.

\subsection{Consenso teórico}

Se a noção para se tornar conceito deve "veicular sobretudo a ideia de univocidade" (Dufays, 2005, p. 87), a leitura literária não remete a essa categoria. De fato, as definições não são totalmente convergentes. Por outro lado, mesmo se as configurações discursivas nas quais elas são enunciadas sejam por vezes um pouco diferentes, os aportes teóricos são suficientemente comuns e constituem um substrato de referências amplamente compartilhadas. É comum ainda o projeto de deslocar o ensino do texto para as interações texto-leitor. Este último ponto me parece totalmente importante. A questão de saber o que é conveniente aprender 
e ensinar na aula de literatura é recorrente, problemática, central e, consequentemente, polêmica. A noção de leitura literária, mesmo se mantendo problemática e plural, sem dúvida produziu consenso teórico didático.

\section{Usos}

Para definir um termo, a lexicologia se apoia no seu uso. É a este exercício que eu vou me dedicar a partir de um segundo conjunto de contribuições.

\subsection{Corpus}

É composto por três coletâneas de artigos compilados a partir dos 9èmes e 11èmes rencontres des chercheurs en didactique de le littérature [IX e XI Encontro de Pesquisadores em Didática da Literatura]. O IX Encontro, organizado em Bordeaux em 2008, resultou na publicação de dois volumes (LOUICHON e ROUXEL 2009a, LOUICHON e ROUXEL, 2009b) e as comunicações do XI Encontro, organizado em Genebra ${ }^{15}$ em 2010, podem ser consultadas no site da Universidade de Genebra, em versão PDF.

Trata-se de ver qual sentido compartilham aqueles que utilizam essa noção e, de maneira mais ampla, qual uso eles fazem nos contextos comuns e constituindo uma comunidade suficientemente circunscrita. Convém, no entanto, relembrar as problemáticas dos dois encontros. Aquelas de Bordeaux intitulavam-se Do corpus escolar à biblioteca interior. Elas procuravam destacar a maneira na qual a escola coloca em relação as obras escolarizadas e a maneira pela qual os alunos constroem uma cultura literária (feita também de relações) a partir desse corpus prescrito e/ou ensinado. As duas publicações geradas por esse colóquio se inscrevem em perspectivas um tanto diferentes. A obra Du corpus scolaire à la bibliothèque intérieure [Do corpus escolar à biblioteca interior], publicada pela Presses Universitaires de Rennes, compila artigos teóricos ou de dimensões histórica ou epistemológica. O segundo, $L a$ Littérature en corpus [A literatura em corpus], publicado pela SCEREN (Services Culture Éditions Ressources pour l'Éducation Nationale), reúne contribuições mais relacionadas às práticas de sala de aula.

Quanto ao encontro de Genebra, as problemáticas se intitulavam Enseigner la littérature dans le souci de la langue [Ensinar a literatura preocupando-se com a língua].

\footnotetext{
${ }^{15}$ Denominado a partir de então Les rencontres des chercheurs en didactique "des littératures" [Encontro de Pesquisadores em Didática das "Literaturas"].
} 


\subsection{Ocorrências}

A expressão leitura literária não figurava em nenhum dos textos enquadrados nas duas manifestações. Aqui está a distribuição que pode ser observada entre o uso ou não uso da expressão.

\begin{tabular}{|c|c|c|c|c|}
\hline Publicações & $\begin{array}{c}\text { Número de } \\
\text { contribuições }\end{array}$ & $\begin{array}{c}\text { Número de } \\
\text { contribuições que } \\
\text { incluem a expressão }\end{array}$ & Percentual & $\begin{array}{c}\text { Número de } \\
\text { contribuições } \\
\text { cujo título inclui } \\
\text { a expressão }\end{array}$ \\
\hline $\begin{array}{c}\text { Bordeaux-PUR } \\
\text { (Presses } \\
\text { Universitaires } \\
\text { de Rennes) }\end{array}$ & 19 & 6 & $31,6 \%$ & 1 \\
\hline $\begin{array}{c}\text { Bordeaux- } \\
\text { SCEREN }\end{array}$ & 25 & 12 & $48 \%$ & 1 \\
\hline Genebra & 52 & 24 & $46 \%$ & 2 \\
\hline TOTAL & 96 & 42 & $44 \%$ & 4 \\
\hline
\end{tabular}

Uma pequena metade das contribuições utiliza a expressão fora do enquadramento proposto pelos organizadores das duas manifestações. Podemos, portanto, considerar que a noção pertence a uma forma de cultura comum dos especialistas em didática da literatura.

\subsection{Definições explícitas}

Sendo a noção de leitura literária relativamente pouco estabilizada, suscetível a acepções diferentes segundo o campo no qual ela se inscreve (literário ou didático) e segundo os autores aos quais ela se refere (Tauveron, Langlade, Rouxel, Dufays, Daunay, os mais presentes), poderíamos esperar que os autores definissem a noção, de uma maneira ou de outra. É o caso de 13 contribuições ${ }^{16}$ de um total de 45 . A definição é feita majoritariamente por meio da referência. Segue um exemplo: "No que concerne à leitura literária, nós nos referimos a Picard (1986) e no que concerne à definição da leitura literária, à Dufays (2005)" (DE PERETTI, SCEREN, 2009b, p. 114). Observamos nesse exemplo a distinção operada entre um

16 Dufays, PUR; de Peretti, Sceren ; de Peretti, Genève ; Belhadjin, Genève ; Delahaye, Genève ; Burdet, Guillemin, Genève ; Deronne, Genève ; Dispy, Genève ; Fourtanier, Genève ; Grader, Genève ; Joole, Genève ; Missiou \& Anagnostopoulo, Genève ; Vrydaghs, Genève. 
teórico da leitura literária e um teórico da didática da leitura literária. Nos 13 textos concernidos, apenas 3 se referem a essas duas categorias ${ }^{17}$.

Em um dos textos há referência apenas a autores fora do campo didático (Ricoeur, Bayard e Bellemin-Noël $)^{18}$, na maioria dos casos, a referência concerne diretamente aos especialistas em didática da literatura. Dufays é citado 8 vezes, Rouxel 3 vezes, Langlade 3 vezes, Tauveron 2 vezes, Falardeau, Dumortier e Louichon são citados uma vez ${ }^{19}$.

É importante observar que apenas três autores explicitam o fato de que a leitura literária não pode ser definida por si só ${ }^{20}$. Missiou e Anagnostopoulo (Genebra) especificam, em nota de rodapé, que "a questão é difícil”.

Vrydaghs (Genebra) define a leitura literária, também em nota, como um "vocábulo", especificando que os especialistas em didática não são unânimes quanto à sua acepção (opondo Rouxel e Dufays). Nessa nota, o autor emprega a expressão com aspas. Este também é o caso de Jean-Louis Dufays (PUR, 2009a).

O uso dessa modalidade autonômica indica que "o enunciador visa ao mundo através do signo, mas o signo resiste, por assim dizer, ao apagamento da transparência, interpondo-se como objeto no trajeto do dizer, impondo-se a ele" (AUTHIER-REVUZ, 2004). Em outras palavras, essa menção da expressão de Jean-Louis Dufays (2008), manifesta a perenidade da ambiguidade e a vontade de significá-la.

O paradoxo é evidente. Embora esse autor seja amplamente utilizado como referência a uma leitura literária cuja definição parece conhecida, óbvia e transparente, ele é praticamente o único autor a negar essa evidência, continuando a evocar a noção de "leitura literária" e obrigando-se a especificar a definição que ele lhe atribui ${ }^{21}$.

\subsection{Definições implícitas}

No entanto, mesmo quando a noção é referenciada, seu significado nem sempre é claro. Sobretudo quando a frase aparece no decorrer do discurso, como uma evidência compartilhada. No entanto, parece-me que é possível traçar algumas distinções e observar os usos da expressão.

\footnotetext{
${ }^{17}$ Dufays, PUR ; de Peretti, Sceren, de Peretti, Genève.

${ }^{18}$ Fourtanier, Genève.

${ }^{19}$ Essas citações referem-se apenas a referências usadas para definir a leitura literária. Alguns desses autores também são amplamente citados em bibliografia.

${ }^{20}$ Dominique Ulma indica em outra obra que seria interessante poder avaliar "os efeitos de certas concepções da leitura literária" (Ulma, 2009a, PUR). No entanto, quando ela utiliza a expressão, ela não a define.

21 "Aí se encontra, como sabemos, todo o desafio da "leitura literária" quando a definimos, após Picard, Jouve e alguns outros como um vaivém combinado entre leituras "ordinárias" e "eruditas".
} 


\section{- A leitura literária = leitura de textos literários}

Essa acepção, já identificada por Jean-Louis Dufays (2005), é ainda presente. Ela aparece claramente nas colocações de Dominique Ulma, por exemplo. No âmbito de um questionário, essa acepção evoca "uma comparação quantitativa da prática de leitura literária" e reformula o item "tempo passado lendo textos literários" em "tempo passado na leitura literária" (ULMA, PUR, p. 224 e p. 226).

Às vezes é mais difícil distinguir com precisão o sentido atribuído pelos autores, mas eu considero que dos 45 textos analisados, 7 remetem mais ou menos a essa acepção ${ }^{22}$. Curiosamente no Encontro de Bordeaux, consagrado ao corpus, portanto aos textos literários, este uso foi quase inexistente. Observemos enfim que esse uso é frequentemente encontrado entre os didáticos do FLE (Francês como Língua Estrangeira) ou FLS (Francês como Língua de Escolarização).

\section{- A leitura literária = um objeto escolar}

Em geral, nos textos, quando os autores falam de leitura literária, eles falam da escola. De fato, a leitura literária remete às competências específicas que a escola deve construir. Assim, Christiane Connan-Pintado fala de um "corpus para construir competências de leitura literária", Sylvie Dardaillon de "sequências de leitura literária”, Sophie David sobre "aquisições dos alunos em matéria de leitura literária", Christine Plu propõe "entrar em leitura literária mediante um suporte particular", Christa Delahaye evoca uma aula na qual "o trabalho de leitura literária" apoia-se sobre "uma progressão pedagógica", Martine Jacques e Daniel Claustre falam "do fim do trabalho de leitura literária", Isabelle de Peretti especifica o que se faz no "domínio da leitura literária" e Jean-Charles Chabanne cita Catherine Dupuy, falando de "professor de leitura literária".

Todas essas citações (e poderíamos propor outras) mostram que a leitura literária é tratada atualmente como inerente à realidade do ensino. Quando falamos de leitura literária, falamos de alunos, de professores, de suportes, de livros didáticos, de dispositivos e de progressões.

\section{- A leitura literária $=$ foco no leitor}

Constatamos que para os autores falar de leitura literária é uma maneira de falar de um ensino da literatura no qual o lugar do leitor é garantido. Assim, Luke Maisonneuve (PUR,

\footnotetext{
${ }^{22}$ Ulma, PUR ; Bomparad, Genève ; Benazoud, Genève ; Brunel, Genève ; De Beaudrap, Genève ; Florey, Genève; Jacquin, Genève.
} 
2009a, p. 77) buscando compreender o que os textos oficiais entendem por leitura literária, foca, antes de tudo, em "uma certa relação com o sujeito leitor". Myriam Tsimbidy (SCEREN, 2009b, p. 211) define a leitura literária em referência clara a Michel Picard: "quer dizer que a leitura literária permite ao leitor compreender para que jogo ele está convidado". Para MarieJosé Fourtanier (Genebra), a leitura literária apela "à criatividade do leitor" e para Gérard Langlade (Genebra), ela necessita de um "investimento subjetivo" e de "uma perspectiva interpretativa". De fato, se o leitor é central, a atividade na qual ele se engaja é maciçamente designada como ligada à interpretação.

Assim, Sylviane Ahr (Genebra) qualifica "a relação dos alunos com a leitura literária: “é esperado deles que se engajem em um processo transacional que os coloquem, eles, leitores singulares, em contato direto com o texto e que eles aprendam a construir seu próprio trajeto interpretativo". Para Gérard Langlade (PUR, 163), a leitura literária e a leitura interpretativa são sinônimas. Martine Champagne (SCEREN, 163) fala da "atividade interpretativa de uma leitura literária" e Anissa Belhadjin (Genebra) considera que a "capacidade de leitura: interpretar", identificada nos programas LEP (Lycée d'enseignement professionnel), remete à leitura literária.

\section{- A leitura literária: uma dinâmica de sala de aula}

Se os alunos são leitores singulares, se ler é interpretar, então a classe torna-se uma "comunidade interpretativa" (LEGOFF, Genebra). As "interações orais", as "trocas" (BURDET \& GUILLEMIN, Genebra), "a palavra compartilhada", “o debate sobre as obras" (PLU, SCEREN, 2009b, p. 187), o cruzamento de interpretações e a colaboração dos leitores (DARDAILLON, SCEREN, 2009b, p. 92), a argumentação (DELAHAYE, Genebra) são privilegiados.

Essa dinâmica de sala de aula apela também a uma "inversão da autoridade interpretativa" (HEBERT, Genebra). Como escreve Sylviane Ahr, não solicitamos mais aos alunos "construir por um jogo de perguntas e respostas, um discurso comum sobre a obra literária, que geralmente é aquele do leitor especialista que é o professor” (AHR, Genebra). Isso não significa que o professor não esteja presente. No dispositivo pedagógico exposto por Christa Delahaye (SCEREN, 2009b, p. 291), o professor constrói uma progressão rigorosa que coloca em tensão discursos diversos sobre a guerra. Assim, ele "permite aos alunos perceber por eles mesmos ${ }^{23}$ o horror da guerra".

\footnotetext{
${ }^{23}$ Destaque realizado pela autora.
} 


\subsection{Consenso prático}

Os pesquisadores em didática da literatura, cujas contribuições constituem o corpus de análise dos usos do sintagma leitura literária, o utilizam abundantemente. Essa noção parece atualmente dotar-se de uma espécie de evidência, porque a sua menção raramente necessita de processo de definição e apresenta até mesmo um uso bastante fraco e frouxo da referência. Deste ponto de vista, a obra de Jean-Louis Dufays, Louis Gemenne e Dominique Ledur, Pour une lecture littéraire [Para uma leitura literária], é citada com muita frequência. A leitura literária, por sua vez, tal como ela emerge dos artigos analisados, deve mais às concepções de Gérard Langlade (para o sujeito leitor) e de Catherine Tauveron (para a noção de interpretação e de comunidade interpretativa). O uso formal da referência aparece mais como uma submissão à retórica da comunicação do que como uma verdadeira ferramenta teórica.

De fato, podemos constatar uma forma de consenso. Falar de leitura literária é falar da escola e do que nela acontece em termos de práticas, de alunos, de professores. Observamos (ver tabela) que as porcentagens menos frequentes do uso da expressão concernem à obra publicada pela editora PUR, mais centrada nas problemáticas gerais e teóricas. As porcentagens mais importantes concernem a obra publicada pela SCEREN, contendo contribuições mais centradas nas práticas de sala de aula ${ }^{24}$. Notaremos ainda que do conjunto das 42 contribuições analisadas, apenas uma refere-se a uma abordagem epistemológica que leva a reinterrogar as concepções da leitura literária (LANGLADE, PUR, 2009a) e apenas uma outra refere-se a uma abordagem puramente teórica (GRADER \& PROD 'HOM, Genebra) ${ }^{25}$. É dizer que a leitura literária não remete mais realmente a um questionamento teórico ${ }^{26}$. Essa constatação merece ser relacionada com a constatação inversa, realizada por Jean-Louis Dufays e Bertrand Daunay em 2007, a partir de um corpus de artigos do período entre 2000 e 2005. Esses autores, buscando uma tipologia das pesquisas em didática da literatura, colocam em evidência a dominação dos estudos teóricos. Eles sugerem que "podemos explicar essa importância pela necessidade de

\footnotetext{
${ }^{24}$ A distinção é muito relativa. Na obra Du Corpus scolaire à la bibliothèque intérieure, encontra-se análises de livros didáticos ou pesquisas com professores. A finalidade destes estudos se refere sobretudo à uma visão histórica, internacional ou teórica.

${ }^{25}$ Essa contribuição, assinada por dois doutorandos, retoma de muito perto à análise de J.L. Dufays à propósito da "leitura literária como noção plural" e propõe "um novo paradigma para a leitura literária" (intitulado o "novo paradigma da leitura literária" de B. Daunay) a partir das teorias de Schaeffer sobre a ficção.

${ }^{26}$ Isso se abre à outras noções, por exemplo, àquela de "biblioteca interior" (FOURTANIER, 2009 e LOUICHON, 2009) ou renova questionamentos, por exemplo, em torno da noção de gênero (BRILLANT-RANOU, 2009 e DENIZOT, 2009).
} 
sempre redefinir melhor certos conceitos que desempenharam um papel estruturante no campo, entre os quais, na linha de frente, leitura e escrita literárias" (DAUNAY; DUFAYS, 2007, p. 12).

A leitura literária não é mais objeto de questionamento teórico. O conceito migrou para discursos de visada mais praxeológica e alcança uma forma de estabilidade e univocidade semânticas. Esse consenso é acompanhado por uma perda de certos aspectos em favor de outros. Por exemplo, a questão da participação e do distanciamento é pouco evocada ${ }^{27}$. Resta uma leitura literária centrada no leitor, realizada em uma aula pensada como uma comunidade interpretativa através da palavra compartilhada.

A título de exemplo, remeto a uma obra que não é exatamente centrada na literatura e trago um enunciado emitido por um professor e não por um pesquisador: "Minha concepção de leitura literária é aquela de um diálogo entre uma obra e as leituras e os leitores plurais" (SOULE, 2008, p. 55).

\section{Conclusão}

Essa definição atestada e bastante unívoca permite pensar a leitura literária como um conceito em uso. Convém para finalizar destacar também que este conceito está ausente de uma outra esfera, a da instituição.

Os documentos de acompanhamento dos programas curriculares de 2002 para a escola primária tiveram um efeito determinante sobre a difusão do conceito. No entanto, ele não está presente em nenhum outro texto oficial, nem nos textos para o Ensino Fundamental I de 2008, nem nos textos para o Ensino Fundamental $\mathrm{II}^{28}$, nem para o Ensino Médio ou para o Ensino Médio profissional, qualquer que seja a data. No entanto, em um artigo recente, Anissa Belhadjin analisa os programas de 2009 para o Ensino Médio profissional e destaca "a nova importância, nestes programas, atribuída à interpretação, e mais geralmente, ao leitor" (BELHADJIN, 2009b, p. 113). Nós não estamos longe, ao que parece, do conceito de leitura literária tal como definido pelo uso feito pelos especialistas em didática da literatura. Falta apenas a expressão que o acompanha.

Por fim, parece-me interessante voltar a uma proposição de Bernard Lahire analisando o uso da noção de "capital cultural" no campo da sociologia. Ele afirma que "essa dialética [...]

\footnotetext{
${ }^{27}$ Ela é relembrada por Micheline Dispy (Genebra) e Anissa Belhadjin (Genebra).

28 Nós encontramos nos programas do Ensino Fundamental II de 2004 a expressão leitura literária (MEN, 2004, 27), empregada em contraponto àquela de leitura documentário. Ela significa, portanto, leitura de textos literários.
} 
tem hoje mais um papel retórico, na economia conceitual das teorias [...] e estratégico em oposição à outras teorias [...] do que um verdadeiro papel teórico visando a construir objetos científicos" (LAHIRE, 1998, p. 299). Parece-me que a leitura literária desempenhou esse papel de catalisador que permitiu ao campo da didática da literatura emergir de maneira específica. Ao falar em leitura literária, ao debater suas possíveis declinações, ao fazer migrar o objeto teórico para o campo da didática, a noção desempenhou um papel retórico e estratégico na autonomização relativa deste domínio de pesquisa.

Em 2010, os organizadores do 1lèmes Rencontres des chercheurs en didactique des littératures [XI Encontro de Pesquisadores em Didática das Literaturas] em Genebra, programaram, ao final do encontro, uma comunicação associando Jean-Louis Dufays e Bertrand Daunay intitulada La lecture littéraire en débat, pour en finir [A leitura literária em debate, para acabar com isso]. A afirmação do fim do debate é a maneira de dizer que existe uma forma de consenso conceitual em torno da leitura literária.

Tais são os resultados que eu alcancei aqui. Talvez tenha sido, para os organizadores desse encontro, uma maneira de afirmar a perda da eficácia do papel retórico e estratégico da noção, ou seja, uma vontade de se contrapor a autonomização do campo da didática da literatura. No entanto, a pesquisa em didática da literatura não poderia reduzir-se a um debate sobre a concepção da leitura literária. Ela trabalha mais amplamente para descrever e avaliar a sua funcionalidade didática, enquanto outras noções ou conceitos são construídos e debatidos no âmbito da comunidade de pesquisadores em didática da literatura.

\section{CORPUS}

\section{Corpus 1}

DAUNAY B. État des recherches en didactique de la littérature. Politiques et rhétoriques de 1' "Ecole juste" avant la Cinquième République. Revue Française de Pédagogie, $\mathrm{n}^{\circ} 159$. INRP, p. 139-189. 2007.

DUFAYS J.-L. La lecture littéraire: une notion plurielle. In: DUFAYS J.; L., GEMENNE; LEDUR D. Pour une lecture littéraire, 4 ed. Bruxelles: De Boeck, 2005. p. 87-97.

ROUXEL A. Qu'entend-on par lecture littéraire? La Lecture et la culture littéraires au cycle des approfondissements. SCEREN, CRDP de Versailles, "Les Actes de la Desco". p. 19-30. 2002.

TAUVERON C. Lire la littérature à l'école. Hatier, 2002. p. 13-23.

\section{Corpus 2a}


LOUICHON B., ROUXEL A. Du corpus scolaire à la bibliothèque intérieure. Rennes: PUR, 2009a.

DUFAYS, J.-L. Le corpus scolaire: analyse de quelques tensions actuelles et éclairage international.

DEMOUGIN, F. Du réseau de l'école primaire au corpus de textes du lycée, comment le système scolaire prend-il «à partie » la littérature?

MAISONNEUVE, L. Comment l'analyse d'une programmation de cycle 3 em littérature (corpus et activités) peut-elle révéler les conceptions littéraires sous-jacentes de leurs auteurs? LANGLADE, G. La didactique de la lecture littéraire entre corpus et théories. BRILLANT RANNOU N., "La configuration du corpus scolaire par les genres: une réalité littéraire ou une nécessité didactique? Le cas de la poésie en lycée"

ULMA D. De corpus scolaire à la bibliothèque intérieur: vers une comparaison internationale.

\section{Corpus 2b}

LOUICHON B., ROUXEL A. La Littérature en corpus. SCEREN, CRDP Bourgogne: 2009b.

BEAUDRAP A.-R. (de). Bibliothèque implicite ou les représentations que les enseignants se font de la transmission d'une culture humaniste.

BELHADJIN A. La place de la littérature de genre dans l'enseignement du français en Lycée Professionnel.

CHAMPAGNE M. La question des valeurs éthiques dans les interactions langagières élaborées à propos d'un texte littéraire.

CLAUSTRE D., JACQUES M. Le corpus et le rhizome.

CONNAN-PINTADO C. Corpus officiels d'albums pour le cycle 3 - D'une 'littérature informée par l'image'.

DARDAILLON S. Quelle place pour l'iconotexte dans les pratiques enseignantes de cycle 3?

DAVID S. D’une bibliothèque de classe à sa bibliothèque intérieure.

DELAHAYE C. La structuration du corpus de littérature dans les classes de cycle 3 et la constitution de la bibliothèque intérieure.

DIAS CHIARUTTINI A. Lectures programmées: programme de littérature au cycle 3 ?

LECLAIRE-HALTE A. L'album au c3: quelle place pour les corpus dans les pratiques enseignantes?

PERETTI I. (de). Culture littéraire au baccalauréat et démocratisation du lycée (1987-2007).

PLU C. Corpus d'œuvres illustrées à l'école. TSIMBIDY M. Elaborer un corpus de formation pour enseigner la littérature de jeunesse aux professeurs des écoles.

\section{Corpus 2c}


11èmes rencontres des chercheurs en didactique des littératures (Genève 2010): Enseigner les littératures dans le souci de la langue ${ }^{29}$.

AHR, S. D'une lecture empirique à une lecture subjective argumentée: quels processus cognitif et langagier les collégiens et les lycéens engagent-ils?

BELHADJIN, A., LOPEZ M. Littérature et langue en LP: quels enjeux pour quels élèves?

BEMPORAD, C. Le CECR et la littérature. Proposition d'une articulation possible. BENAZOUT, O. Le rôle de la littérature de jeunesse dans l'acquisition du français.

BRUNEL, M. Les nouveaux programmes du français au collège en France: nouveaux enjeux pour la langue et la littérature?

BURDET, C.; GUILLEMIN S. Compréhension, interprétation et souci de la langue: comment les cercles de lecture peuvent-ils inscrire ce triangle actif?

CHABANNE J.-C. "Tu vas dans le texte et tu relèves les mots": enseigner la littérature dans le souci du lexique, entre grammaire, style, et attention au texte.

DE BEAUDRAP, A.-R. La littérature européenne au risque de l'enseignement du français.

DE PERETTI, I. Théâtre de jeunesse et développement des compétences de lecture: comparaison des dispositifs et des gestes professionnels dans deux classes du cycle 3 et deux classes de collège.

DARDAILLON, S. Emergence d'un rapport à la langue et au texte à travers les expériences de lecture de l'œuvre de Béatrice Poncelet. DEMOUGIN, F. Construire des automatismes linguistiques et culturels en q classe de littérature.

DERONNE, C. Quelle communication didactique dans la classe de français au service de la complexité de la lecture littéraire.

DISPY, M. Conjuguer enseignement de la langue et activités propres a l'adoption d'une posture appropriée a la compréhension comme à la production d'écrits littéraires.

FLOREY, S. Ateliers d'écriture, écrivains et école: entre désacralisation du texte littéraire et facteur de transmission.

FOURTANIER, M.-J. Le rôle de la langue dans la mise en texte de la réception d'une œuvre littéraire.

HEBERT, M. Observation des gestes spécifiques d'étayage pour l'intégration réussie d'un élève en difficulté d'apprentissage en classe de littérature au secondaire.

JACQUIN, M. Quelle place pour l'enseignement des littératures étrangères au sein d'une perspective actionnelle? JOOLE, P. Enseigner la littérature à l'école en faisant tenir un carnet de lecture.

LE GOFF, F. Interaction lecture/écriture et enseignement de la littérature: Quelles articulations didactiques? LANGLADE, G. De l'opacité linguistique à l'actualisation des œuvres.

MISSIOU, M., ANAGNOSTOPOULOU D. La bande dessinée - œuvre littéraire en classe de Français langue étrangère (FLE): étude de cas en Grèce.

\footnotetext{
${ }^{29} \mathrm{http} / / /$ www.unige.ch/litteratures2010/contributions.html (consultado em 21/12/2010)
} 
PROD'HOM, T.; GRABER, S. Le sujet dans le texte - Un nouveau paradigme pour la lecture littéraire.

RICHARD, S.; LECAVALIER, J. Langue et littérature, outils gigognes de la construction identitaire et de la représentation du monde.

RIQUOIS, E. Exploitation pédagogique du texte littéraire et lecture littéraire en FLE: un équilibre fragile.

VRYDAGHS, D. Coordonner l'apprentissage de l'interprétation et celui de la langue. L'exemple des romans méta sémiotiques.

\section{Referências}

AUTHIER-REVUZ, J. Le fait autonymique: Langage, langue, discours: quelques repères. In: AUTHIER-REVUZ, M; DOURY, REBOUL-TOURE S. (Org.). Parler des mots: le fait autonymique en discours. Presses de la Sorbonne Nouvelle, (2004). p. 67-96.

BELHADJIN, A. Nouvelles approches de la lecture en lycée professionnel. In: BUTLEN, M.; HOUDARD-MEROT V. (Org.). Interpréter et transmettre la littérature aujourd'hui. CergyPontoise: Encrage Université, 2009. p. 105-121.

BRILLANT RANNOU, N. La configuration du corpus scolaire par les genres : une réalité littéraire ou une nécessité didactique? Le cas de la poésie en lycée », LOUICHON B., ROUXEL A. Du corpus scolaire à la bibliothèque intérieure. Rennes: PUR, 2009.

BURGOS, M. Lecteurs experts, lecteurs convers, de quelques lecteurs en lycée professionnel et ailleurs. L’interprétation des textes. Pratiques, nº76, Metz. 1992.

DAUNAY, B. La 'lecture littéraire': les risques d'une mystification. Recherches, ${ }^{\circ} 30$, Lille. 1999

DAUNAY, B. État des recherches en didactique de la littérature. Politiques et rhétoriques de 1' "Ecole juste" avant la Cinquième République. Revue Française de Pédagogie, n 159. INRP, p. 139-189. 2007.

DAUNAY, B; DUFAYS, J.-L. Méthodes de recherche en didactique de la littérature. La lettre de l'AIRDF, n'40, p. 8-13. 2007.

DUFAYS J.-L. Les lectures littéraires : évolution et enjeux d'un concept. Tréma, $\mathrm{n}^{\circ} 19$, IUFM de Montpellier. 2002.

DUFAYS, J.-L.; GEMENNE, L.; LEDUR, D. Pour une lecture littéraire. 2ème édition, Bruxelles: De Boeck, 2005.

DENIZOT, N. Construction d'un corpus scolaire: les extraits de Balzac dans les manuels scolaires (1880-2007). In: LOUICHON, B.; ROUXEL, A. Du corpus scolaire à la bibliothèque intérieure. Rennes: PUR, 2009.

FOURTANIER, M.-J. Entre corpus légitimes et lectures buissonnières, la formation du sujet lecteur. In: LOUICHON, B.; ROUXEL, A. Du corpus scolaire à la bibliothèque intérieure. Rennes: PUR, 2009.

GERVAIS, B.; BOUVET, R. Théories et pratiques de la lecture littéraire. Québec: PUQ, 2007. 
LAHIRE, B. L'Homme pluriel. Les Ressorts de l'action. [Nathan], Armand Colin/Nathan (Pluriel), 1998.

LANGLADE, G. La didactique de la lecture littéraire entre corpus et théories. In: LOUICHON, B.; ROUXEL, A. Du corpus scolaire à la bibliothèque intérieure. Rennes: PUR, 2009.

LOUICHON B. Du discours didactique au texte institutionnel. Enseignement de la langue. Crise, tension ? Le Français aujourd'hui, n 156, Armand Colin, p. 15-23. 2007.

LOUICHON B. Les rayons imaginaires de nos bibliothèques intérieures. In: LOUICHON, B.; ROUXEL, A. Du corpus scolaire à la bibliothèque intérieure. Rennes: PUR, 2009.

MEN. Qu'apprend-on à l'école élémentaire?. CNDP/XO Editions, 2002a.

MEN. Littérature. Documents d'accompagnements des programmes. CNDP, 2002b.

MEN. Lire et écrire au cycle 3. Documents d'accompagnements des programmes. CNDP, 2003.

MEN. Enseigner au collège. Français. Programme et accompagnement. CNDP, 2004.

REUTER, Y. La lecture littéraire : éléments de définition. In: DUFAYS, J.-L.; GEMENNE, L., LEDUR, D. (Org.). Pour une lecture littéraire 2. Bruxelles: De Boeck Duculot, 1996. p. $33-41$.

ROSIER J.-M. La Didactique du français. PUF: 2002. (Que sais-je ?).

ROUXEL, A. Enseigner la lecture littéraire. Rennes: PUR, 1996.

SOULE, Yves. Troisième étude de cas : débat philo ou débat littéraire?. In: BUCHETON D.; DEZUTTER, O. (Org.). Le Développement des gestes professionnels dans l'enseignement du français. Un défi pour la recherche et la formation. Bruxelles: De Boeck, 2008. p. 53-58. 